\section{A) Check for updates}

Cite this: Org. Chem. Front., 2020, 7 2634

\title{
Dimerization-cyclization reactions of isocyanoaryl-tethered alkylidenecyclobutanes via a triplet biradical mediated process $\uparrow$
}

\author{
Le-Yi Tao, Yin Wei (iD * and Min Shi (iD)
}

A triplet biradical mediated dimerization-cyclization reaction of isocyanoaryl-tethered alkylidenecyclobutanes has been reported in this paper, giving a new protocol for the construction of macrocyclic skeletons including dihydroquinoline and quinoline units in moderate yields. The reaction proceeded through a key 1,4-diazabutatriene intermediate along with intramolecular redox to produce a biradical intermediate species, which subsequently experienced bond-breaking and-making processes to give the desired product. The reaction mechanism was supported by density functional theory (DFT) calculations.

Received 23rd July 2020 Accepted 30th July 2020

DOI: $10.1039 / \mathrm{d} 0 \mathrm{qo} 00878 \mathrm{~h}$

rsc.li/frontiers-organic

\section{Introduction}

Isocyanides are pivotal intermediates in organic synthesis and have been widely used to synthesize a diversity of nitrogen-containing compounds, including new drugs and natural products. ${ }^{1}$ For example, they can easily insert into various $\mathrm{C}-\mathrm{C}$, $\mathrm{C}-\mathrm{X}$ or $\mathrm{X}-\mathrm{X}(\mathrm{X}=$ heteroatom $)$ chemical bonds to rapidly construct complex molecules. ${ }^{2}$ Moreover, they can also undergo diverse radical cyclizations to provide aromatic heterocyclic compounds; ${ }^{3}$ function as ligands to coordinate with transition metals to realize further transformations; ${ }^{4}$ act as zwitterion intermediates to accept nucleophilic attacks; ${ }^{5}$ and perform as key intermediates for multi-component reactions. ${ }^{6,5 h, i}$

The dimerization of isocyanides has also been employed to furnish aromatic heterocyclic compounds, ${ }^{7}$ which can be classified as homodimerization and heterodimerization. In 1977, Lange and Höfle reported the synthesis of 2,2-diphenyl4,4'-bis-quinazolines via a head to head C-C bond homodimerization of two $\mathrm{N}$-imidoyl isocyanides. ${ }^{7 a}$ Later on, Yamamoto and co-workers developed a new and efficient synthetic method to produce a novel class of 1,4-disubstituted imidazoles via heterodimerization of two different isocyanides in $2006{ }^{7 b}$ Subsequently, Cheng's group employed the homodimerization of 2-pyridylisonitriles to rapidly construct $\pi$-extended fused heteroarenes, which are novel selective colorimetric and optical probes for copper ions. ${ }^{7 c}$ Moreover,

State Key Laboratory of Organometallic Chemistry, Shanghai Institute of Organic Chemistry, Chinese Academy of Sciences, 345 Lingling Road, Shanghai 200032, China.E-mail:weiyin@sioc.ac.cn

$\dagger$ Electronic supplementary information (ESI) available: Experimental procedures, characterization data of new compounds. CCDC 1509688. For ESI and crystallographic data in CIF or other electronic format see DOI: 10.1039/ d0qo00878h
Hong and Xu also independently reported the cycloaddition of two different isocyanides to synthesize the corresponding 1,4-diaryl- $1 H$-imidazoles and pyrrolo[3,4-b]indoles in good yields, respectively. ${ }^{7 d, e}$ However, to the best of our knowledge, the homodimerization of isocyanides through a biradical process has not been reported yet.

In 2017, our group reported a novel formal [3+1] cyclization reaction of isocyanoaryl-substituted alkylidenecyclopropanes for the synthesis of 1,2-dihydrocyclobuta[b]quinoline derivatives in moderate to excellent yields (Scheme 1, previous work). ${ }^{8}$ We proposed that this cyclization reaction proceeded through an intramolecular nucleophilic attack of the isocyanide group to the $\mathrm{C}=\mathrm{C}$ double bond, $\mathrm{Ag}$ ion elimination and cyclopropane ring expansion, furnishing 1,2-dihydrocyclobuta $[b]$ quinoline derivatives. On the basis of this previous work, we envisaged that if isocyanoaryl-tethered alkylidenecyclobutanes are used as substrates to conduct the same reaction, the cyclobutane ring expansion could also be realized. However, we found that upon heating at $140{ }^{\circ} \mathrm{C}$, an unexpected quinoline and dihydroquinoline product derived from homodimerization and cyclization was obtained in moderate yield (Scheme 1, this

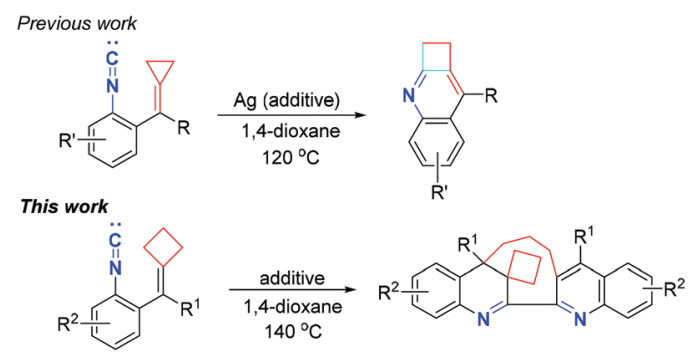

Scheme 1 Previous work and this work. 
work). Quinoline and dihydroquinoline skeletons are an important class of heterocycles in natural products, and are widely found in alkaloids and pharmaceuticals, possessing diverse pharmacological properties such as anti-bacterial, ${ }^{9}$ anti-cancer, ${ }^{10}$ anti-HIV ${ }^{11}$ and so on. ${ }^{12}$ In particular, in 2015, Pal and co-workers reported the design and preparation of a new hybrid template by linking quinoline, triazole and dihydroquinoline together as pharmacophoric groups, disclosing that this library of molecules could work as potential cytotoxic agents for the inhibition of cancer cells and PDE48 in vitro. ${ }^{13}$ Although numerous useful synthetic methods have been developed to construct quinoline ${ }^{14}$ and dihydroquinoline $^{15}$ related core structures, the exploration of novel and efficient synthetic protocols for the rapid construction of quinoline and dihydroquinoline skeletons is still required at the present stage. This unprecedented result stimulated us to further explore this reaction because the mixed quinoline and dihydroquinoline scaffold may have special biological activities. Herein, we wish to report a novel biradical-mediated dimerization-cyclization reaction of isocyanoaryl-tethered alkylidenecyclobutanes to synthesize macrocyclic skeletons containing dihydroquinoline and quinoline units.

\section{Results and discussion}

\section{Experimental investigations}

We first utilized substrate $\mathbf{1 a}$ as a model substrate for the initial examination in the presence of $\mathrm{Ag}_{2} \mathrm{CO}_{3}(5 \mathrm{~mol} \%)$ as the additive at $140{ }^{\circ} \mathrm{C}$ in 1,4-dioxane under an argon atmosphere and found that the desired macrocyclic product 2a was obtained in 33\% NMR yield within $24 \mathrm{~h}$ (Table 1, entry 1). The structure of $\mathbf{2 a}$ has been unambiguously determined by X-ray diffraction, and its crystal data are presented in the ESI. $\dagger$ We further optimized the reaction conditions, and the results are summarized in Table 1. Using various Lewis acidic additives such as AgNTf ${ }_{2}, \mathrm{Zn}\left(\mathrm{NTf}_{2}\right)_{2}, \mathrm{Cu}(\mathrm{OTf})_{2}$, TlOAc, In(OTf $)_{3}, \mathrm{Fe}(\mathrm{OTf})_{2}$ and $\mathrm{BF}_{3} \cdot \mathrm{Et}_{2} \mathrm{O}$ in this reaction, we identified that TlOAc was the best Lewis acidic additive for this dimerization-cyclization reaction, affording $2 \mathrm{a}$ in $42 \%$ yield, presumably due to that it is the most stable additive at such high temperature (entries $2-8$ ). Next, we found that the reaction could also proceed in the absence of any additive, giving $2 \mathbf{a}$ in $37 \%$ yield (entry 9). The examination of solvent effects revealed that the use of other organic solvents such as DMF, toluene, anisole and cyclohexanone could also afford 2a in moderate yields ranging from $32 \%$ to $42 \%$, indicating that 1,4 -dioxane, toluene and anisole were the solvent of choice (entries 10-13). Then, we chose 1,4-dioxane as the solvent and TIOAc as the additive for further optimization of the reaction conditions. Lowering the reaction temperature to $130{ }^{\circ} \mathrm{C}$ furnished $2 \mathrm{a}$ in $20 \%$ yield, and raising the reaction temperature to $150{ }^{\circ} \mathrm{C}$ did not improve the yield of 2a in 1,4-dioxane (entries 14 and 15). Further increasing the employed amount of TlOAc did not improve the yield of $2 \mathrm{a}$, suggesting that $5 \mathrm{~mol} \%$ of TlOAc should be used in this reaction (entry 16). In addition, lengthening or shortening the
Table 1 Optimization of the reaction conditions ${ }^{a}$

\begin{tabular}{|c|c|c|c|c|}
\hline Entry & Additive & Temp. $\left({ }^{\circ} \mathrm{C}\right)$ & Solvent & Yield $^{b} / \%$ \\
\hline 1 & $\mathrm{Ag}_{2} \mathrm{CO}_{3}$ & 140 & 1,4-Dioxane & 33 \\
\hline 2 & $\mathrm{AgNTf}_{2}$ & 140 & 1,4-Dioxane & 21 \\
\hline 3 & $\mathrm{Zn}\left(\mathrm{NTf}_{2}\right)_{2}$ & 140 & 1,4-Dioxane & - \\
\hline 4 & $\mathrm{Cu}(\mathrm{OTf})_{2}$ & 140 & 1,4-Dioxane & - \\
\hline 5 & TlOAc & 140 & 1,4-Dioxane & 42 \\
\hline 6 & $\operatorname{In}(\mathrm{OTf})_{3}$ & 140 & 1,4-Dioxane & - \\
\hline 7 & $\mathrm{Fe}(\mathrm{OTf})_{2}$ & 140 & 1,4-Dioxane & 20 \\
\hline 8 & $\mathrm{BF}_{3} \cdot \mathrm{Et}_{2} \mathrm{O}$ & 140 & 1,4-Dioxane & - \\
\hline 9 & 一 & 140 & 1,4-Dioxane & 37 \\
\hline 10 & TlOAc & 140 & $\mathrm{DMF}$ & 37 \\
\hline 11 & TlOAc & 140 & Toluene & 42 \\
\hline 12 & TlOAc & 140 & Anisole & 42 \\
\hline 13 & TlOAc & 140 & Cyclohexanone & 32 \\
\hline 14 & TlOAc & 130 & 1,4-Dioxane & 20 \\
\hline 15 & TlOAc & 150 & 1,4-Dioxane & 37 \\
\hline $16^{c}$ & TlOAc & 140 & 1,4-Dioxane & 41 \\
\hline $17^{d}$ & TlOAc & 140 & 1,4-Dioxane & 18 \\
\hline $18^{e}$ & TlOAc & 140 & 1,4-Dioxane & 40 \\
\hline $19^{f}$ & TlOAC & 140 & 1,4-Dioxane & $45(40)$ \\
\hline $20^{g}$ & TlOAc & 140 & 1,4-Dioxane & 39 \\
\hline
\end{tabular}

${ }^{a}$ Unless otherwise specified, all reactions were carried out using 1a $(0.1 \mathrm{mmol})$, additive $(5 \mathrm{~mol} \%)$ in solvent $(1.0 \mathrm{~mL}), 140{ }^{\circ} \mathrm{C}, 24 \mathrm{~h}$. ${ }^{b}$ Yields were determined by ${ }^{1} \mathrm{H}$ NMR spectroscopy using $1,3,5$-trimethoxybenzene as an internal standard and isolated yield is given in parentheses. ${ }^{c}$ Additive: $20 \mathrm{~mol} \%$. ${ }^{d}$ Reaction time: $12 \mathrm{~h}$. ${ }^{e}$ Reaction time: $36 \mathrm{~h}$. ${ }^{f}$ Purging oxygen gas in the solvent. ${ }^{g}$ Adding molecular sieves $4 \AA$ (50 mg).

reaction time did not give $\mathbf{2 a}$ in better yields (entries 17 and 18). Purging the oxygen gas from the solvent could improve the yield of $2 \mathrm{a}$ to $45 \% \mathrm{NMR}$ yield ( $40 \%$ isolated yield) and adding molecular sieves $4 \AA$ to get rid of the trace water in the solvent did not improve the yield of 2a (entries 19 and 20). To summarize, this dimerization-cyclization reaction should be carried out in degassed 1,4-dioxane using TlOAc (5 mol\%) as the additive at $140{ }^{\circ} \mathrm{C}$ within $24 \mathrm{~h}$ (for more detailed information, see Tables S1-S3 in the ESI $\dagger$ ).

With the optimal conditions in hand, we investigated the generality of this dimerization-cyclization reaction using various isocyanoaryl-tethered alkylidenecyclobutanes $\mathbf{1 b} \mathbf{- 1 w}$ as substrates and the results are elucidated in Table 2 . When the $\mathrm{R}^{1}$ group is an aromatic substituent, substrates $\mathbf{1 b} \mathbf{- 1 e}$, having an electron-poor aromatic ring, gave the desired products 2b-2e in moderate yields ranging from $44 \%$ to $58 \%$. However, substrates $\mathbf{1 f - 1 k}$, having an electron-rich aromatic ring, furnished the corresponding products in the yields depending on the position of the substituent at the aromatic ring. When the $-\mathrm{CH}_{3}$ or $-\mathrm{OCH}_{3}$ group was present at the meta-position of the benzene ring, the corresponding products $\mathbf{2} \mathbf{g}$ and $\mathbf{2 k}$ were obtained in $56 \%$ and $48 \%$ yields, respectively. However, when the $-\mathrm{CH}_{3}$ or $-\mathrm{OCH}_{3}$ group was present at the ortho- or paraposition, products $2 \mathbf{f}, \mathbf{2 h}$ or $2 \mathbf{j}$ were obtained in lower yields, indicating that the substituent position effects have a signifi- 
Table 2 Substrate scope of 1 for the homodimerization reaction ${ }^{a, b}$

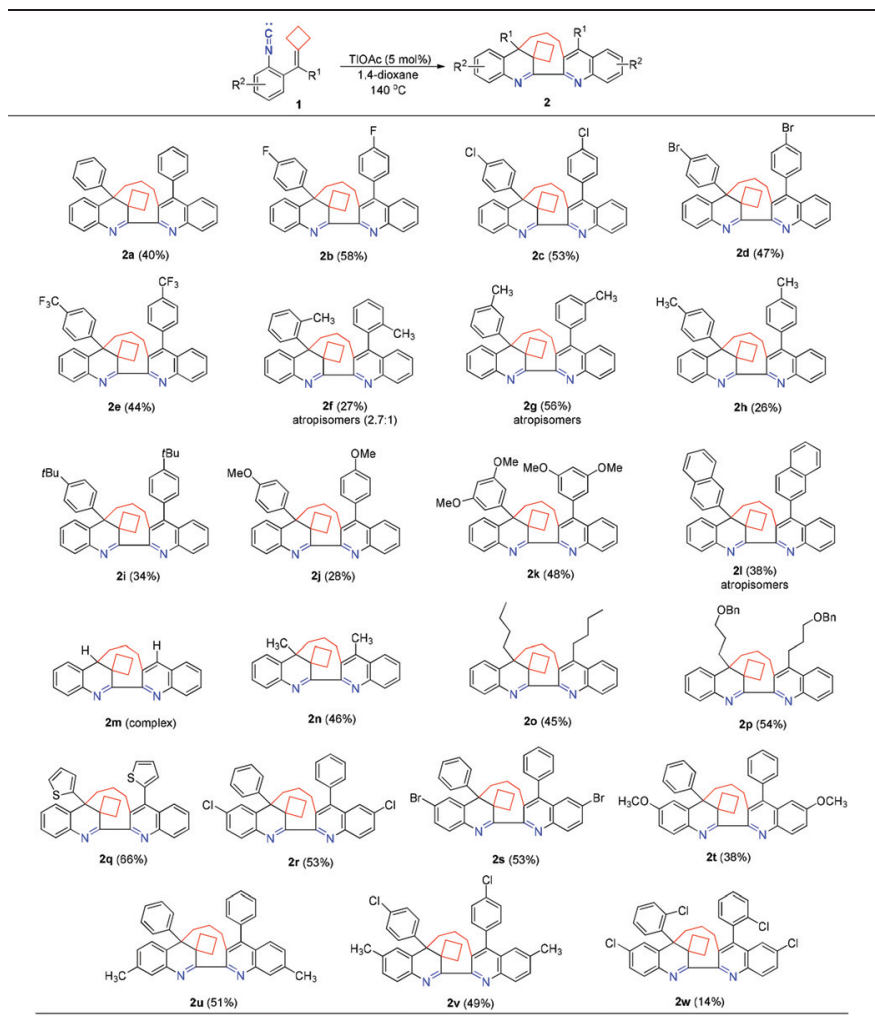

${ }^{a}$ Unless otherwise specified, all reactions were carried out using 1 $(2 \mathrm{mmol})$, TlOAc $(5 \mathrm{~mol} \%)$ in degassed 1,4 -dioxane $(4.0 \mathrm{~mL}), 140{ }^{\circ} \mathrm{C}$, $24 \mathrm{~h}$, under an Ar atmosphere. ${ }^{b}$ Isolated yield.

cant impact on product yields. Substrate 1i bearing a sterically bulky and electron-rich tert-butyl group at the para-position of the benzene ring could deliver the desired product $2 \mathbf{i}$ in $34 \%$ yield. Substrate $\mathbf{1 1}$, in which the $\mathrm{R}^{1}$ group is a 2-naphthyl group, provided the desired product $2 \mathbf{l}$ in $38 \%$ yield as atropisomers. When $\mathrm{R}^{1}$ is a hydrogen atom, the reaction only gave a complex product without the formation of the desired product. Substrates 1n-1p with aliphatic substituents were also tolerated, giving the corresponding products $2 \mathbf{n}-2 \mathbf{p}$ in $46 \%, 45 \%$ and $54 \%$ yields, respectively. When $\mathrm{R}^{1}$ is a thiophene substituent, the corresponding product $2 \mathrm{q}$ could be obtained in $66 \%$ yield, suggesting that this reaction is compatible with heteroaromatic rings. We also examined the substituent effect at the isocyanoaryl moiety and found that the substituents could be halogen atoms, methyl or methoxy groups and had little influence on the reaction proceeding, affording the desired products $2 \mathbf{r}-\mathbf{2 u}$ in $38 \%-53 \%$ yields. Substrates $\mathbf{1 v}$ and $\mathbf{1 w}$ having a substituent on each benzene ring were also tolerated, furnishing the desired products $2 \mathbf{v}$ and $2 \mathbf{w}$ in $49 \%$ and $14 \%$ yields.

\section{Mechanistic studies}

Next, we focused on investing the mechanism of this dimerization-cyclization reaction. The suggested ionic reaction mechanism of isocyanoaryl-substituted alkylidenecyclopropane (ACP) $\mathbf{1}^{\prime}$ is shown in Scheme 2 (previous work). ${ }^{8}$ Initially, the $\mathrm{C}=\mathrm{C}$

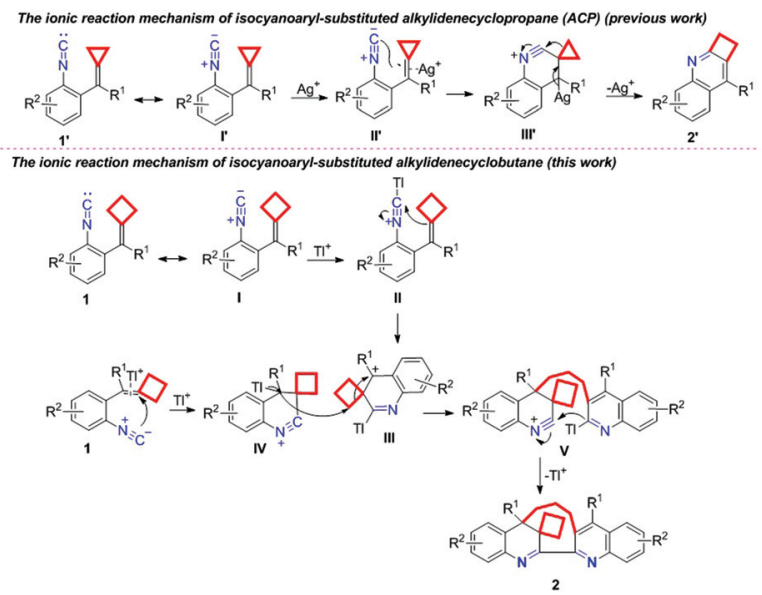

Scheme 2 The proposed reaction mechanisms for previous work and this work.

double bond of ACP I' was activated by $\mathrm{Ag}^{+}$ions to furnish an intermediate II', which subsequently underwent an intramolecular nucleophilic attack to afford intermediate III'. Finally, the elimination of $\mathrm{Ag}^{+}$and cyclopropane ring expansion gave the corresponding product 2 '. According to the above mechanism, a plausible ionic reaction mechanism for isocyanoaryl-substituted alkylidenecyclobutane is first proposed as shown in Scheme 2. Substrate 1 can have its resonance structure I, in which the isocyanide group is initially activated by $\mathrm{Tl}^{+}$ions to receive the intramolecular nucleophilic attack of the cyclobutyl group, affording an intermediate III. On the other hand, the $\mathrm{C}=\mathrm{C}$ double bond in another molecule of substrate 1 can also receive the intramolecular nucleophilic attack of the isocyanide group at high temperature to give an intermediate IV, which reacts with intermediate III through an intermolecular nucleophilic attack along with the cyclobutane ring-opening process to afford intermediate $\mathbf{V}$. The subsequent intramolecular addition along with the release of $\mathrm{TI}^{+}$delivers the desired product 2 .

Then, we embarked DFT studies on these proposed ionic mechanisms for previous work and this work. For the DFT studies on the proposed ionic mechanism of previous work, all calculations have been performed at the SMD/M06/ 6-311+G(d,p)/LANL2DZ//B3LYP/6-31G(d)/LANL2DZ level with the Gaussian 09 program. The solvation Gibbs free energy profile in 1,4-dioxane for the suggested reaction pathway is shown in Fig. $1\left(\Delta G_{298}\right.$ ( $\left.\mathrm{kcal} \mathrm{mol}^{-1}\right)$, see ESI $\dagger$ for the details). This reaction pathway includes two steps. The first one is the activation of the $\mathrm{C}=\mathrm{C}$ double bond of isocyanoaryl-substituted alkylidenecyclopropane by silver(I) ions to undergo an intramolecular nucleophilic attack, giving intermediate $\mathbf{A}^{\prime}$ through transition state $\mathbf{T S} \mathbf{1}^{\prime}$ with an energy barrier of $22.3 \mathrm{kcal} \mathrm{mol}^{-1}$. The second step is the intermediate $\mathbf{A}^{\prime}$ passing through TS2' with an energy barrier step up to $35.1 \mathrm{kcal} \mathrm{mol}^{-1}$ to furnish the corresponding product via the elimination of $\mathrm{Ag}^{+}$and cyclopropane ring expansion process, which is the rate-determining step in the reaction. Moreover, the total $\Delta G_{298}$, rxn in 


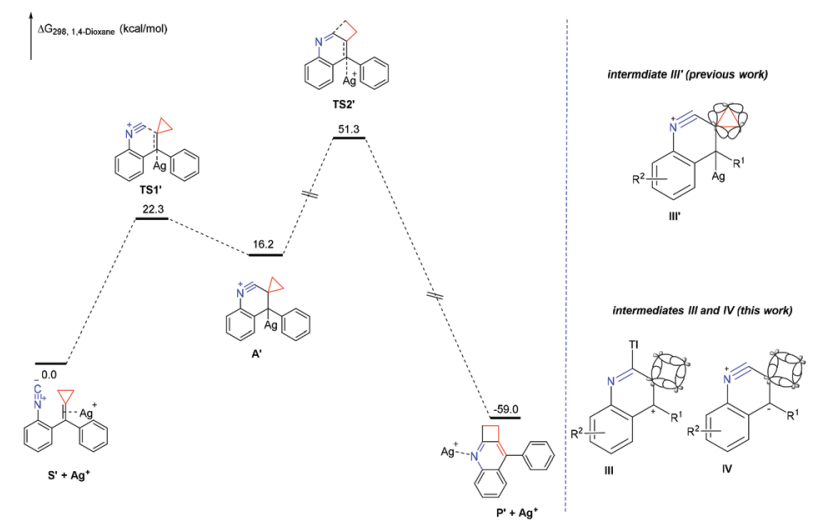

Fig. 1 DFT calculation on the reaction pathway via the ionic mechanism of previous work (relative Gibbs energy values in 1,4-dioxane solution are given in $\mathrm{kcal} \mathrm{mol}^{-1}$ ).

1,4-dioxane of this reaction is $-59.0 \mathrm{kcal} \mathrm{mol}^{-1}$ overall, accounting for a thermodynamically favorable process.

The proposed ionic mechanism of this work was also investigated by DFT calculations using the SMD/M06/6-311+G(d,p)// B3LYP/6-31G(d) level of theory with the Gaussian 09 program. To simplify the calculation process, we investigated the reaction pathway starting from substrate 1a without TlOAc additive. However, the suggested intermediates III or IV could not be located after several attempts by the DFT calculations. Moreover, another plausible ionic reaction mechanism is also investigated and shown in Scheme S6 in the ESI, $\uparrow$ which could not be supported by the DFT calculations as well. Therefore, we hypothesize that this dimerization-cyclization reaction may proceed through a different pathway from the aforementioned proposed ionic mechanism. Through the comparison of these two ionic reactions, we could recognize that the difference is the instability of intermediates III and IV. According to the Fröster-Coulson-Moffitt model, Walsh model ${ }^{16}$ and Dewar's $\sigma$ conjugation conception, ${ }^{17}$ the carbon-carbon bond of cyclopropane is similar to an unsaturated $\mathrm{C}=\mathrm{C}$ double bond. Therefore, the cyclopropane moiety could conjugate to the neighbouring electron-deficient part, contributing to the stability of intermediate III'. For cyclobutane units lacking similar properties, the formations of intermediate III or IV are impossible (Fig. 1).

The ionic mechanism of this dimerization-cyclization reaction does not work, leading us to think about other possibilities for the mechanism. According to Xu's work, ${ }^{7 e-i}$ we think that our work may also go through a 1,4-diazabutatriene mechanism. We first proposed a similar ionic mechanism shown in Scheme S7 in the ESI. $\dagger$ Unfortunately, this ionic mechanism cannot be supported by the DFT calculations since the key intermediate cannot be located. Considering that the reaction was conducted at $140{ }^{\circ} \mathrm{C}$, we hypothesize that this reaction may involve a free-radical mechanism, which is generated by intramolecular redox at high temperature.

As a radical mediated process, a plausible biradical mechanism for this dimerization-cyclization reaction is outlined in

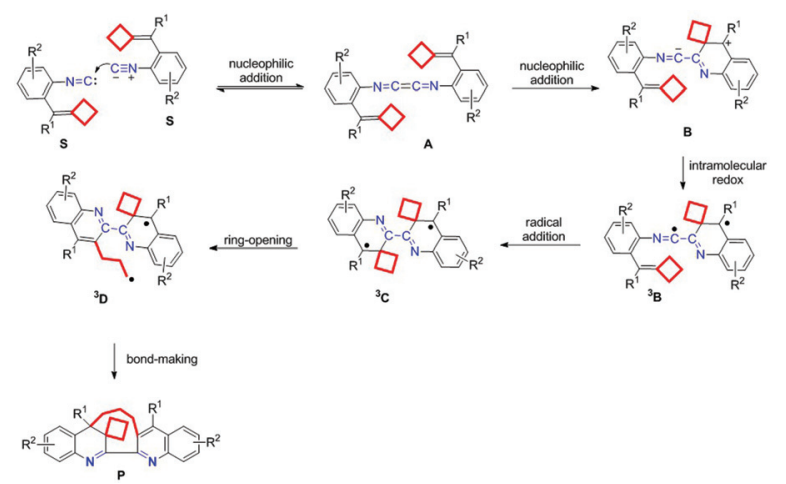

Scheme 3 Proposed biradical reaction mechanism.

Scheme 3. Initially, the isocyanide carbon of one substrate undergoes a nucleophilic attack on the isocyanide carbon of another substrate to give a 1,4-diazabutatriene intermediate $\mathbf{A}$. Then, one $\mathrm{C}=\mathrm{C}$ double bond of intermediate $\mathbf{A}$ undergoes the intramolecular nucleophilic attack on the 1,4-diazabutatriene unit, generating the intermediate $\mathbf{B}$, which subsequently experiences an intramolecular redox process to furnish a biradical intermediate ${ }^{3} \mathbf{B}$. Next, a radical addition to the $\mathrm{C}=\mathrm{C}$ double bond takes place to furnish an intermediate ${ }^{3} \mathbf{C}$, which initiated the cyclobutane ring-opening to produce a biradical intermediate ${ }^{3} \mathbf{D}$. Finally, the intermediate ${ }^{3} \mathbf{D}$ undergoes a bond-making process to give the desired product. The Lewis acidic additive of TlOAc, which is quite stable at high temperature, probably can activate both the isocyano-group through $\sigma$ coordination and the $\mathrm{C}=\mathrm{C}$ double bond by $\pi$-coordination, facilitating the reaction proceeding and improving the yield of this dimerization-cyclization reaction product. The key issue of this newly proposed reaction mechanism is the formation of 1,4-diazabutatriene and the biradical intermediates as well as their reaction properties.

The possible reaction mechanisms along the singlet or triplet pathways were all investigated theoretically. We first calculated the possible singlet pathway. The species reported in this paper are denoted as ${ }^{m}$ ITEMx, where $m=1$ for singlet and 3 for triplet spin state multiplicities; ITEMx = TSx for a transition state, A-D for a reaction intermediate, $\mathbf{S}$ for the substrate and $\mathbf{P}$ for the product. The solvation Gibbs free energy profile in 1,4-dioxane for the suggested reaction pathway is shown in Fig. $2\left(\Delta G_{298}\left(\mathrm{kcal} \mathrm{mol}^{-1}\right)\right.$, see ESI $\dagger$ for the details). First, the reaction starting from substrate complex $\mathbf{S}$ proceeds through nucleophilic attack of the isocyanide carbon of one substrate on the isocyanide carbon of another substrate, to form 1,4-diazabutatriene A via TS1 with an energy barrier of $18.0 \mathrm{kcal}$ $\mathrm{mol}^{-1}$. Subsequently, the intramolecular nucleophilic attack of the $\mathrm{C}=\mathrm{C}$ double bond on the 1,4-diazabutatriene unit furnishes the intermediate $\mathbf{B}$ via transition state TS2 with an energy barrier up to $14.4 \mathrm{kcal} \mathrm{mol}^{-1}$. Then, the intermediate $\mathbf{B}$ is excited from the ground state to the triplet state biradical species ${ }^{3} \mathbf{B}$ with $14.0 \mathrm{kcal} \mathrm{mol}^{-1}$. Next, a subsequent radical addition process takes place to generate an intermediate ${ }^{3} \mathbf{C}$ 


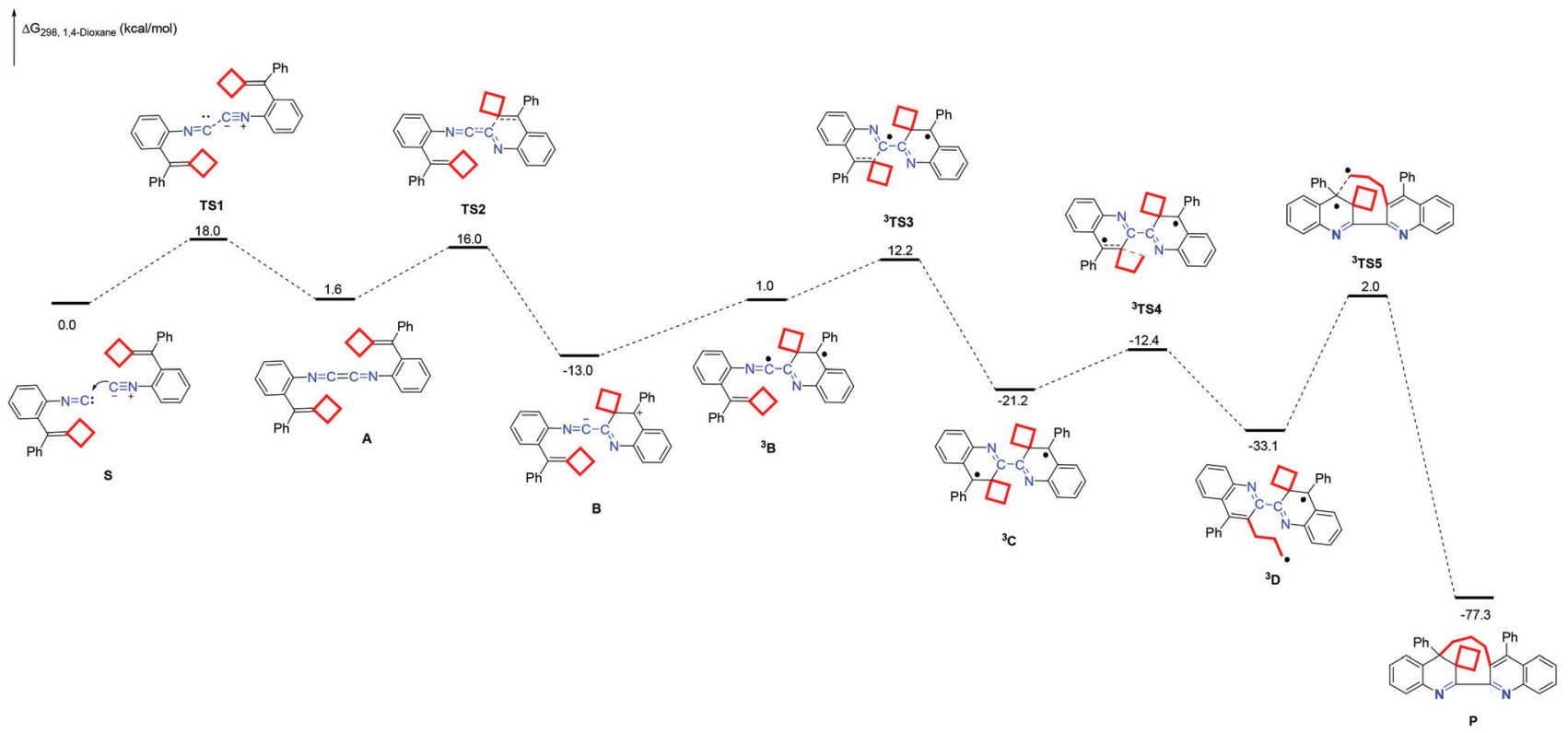

Fig. 2 Solvation Gibbs free energy profile for the reaction of 1a. (Relative Gibbs energy values in 1,4-dioxane solution are given in kcal mol ${ }^{-1}$.)

through ${ }^{3}$ TS3 with an energy barrier of $11.2 \mathrm{kcal} \mathrm{mol}{ }^{-1}$. Subsequently, the intermediate ${ }^{3} \mathbf{C}$ undergoes a cyclobutane ring-opening to deliver an intermediate ${ }^{3} \mathrm{D}$ through the transition state ${ }^{3}$ TS4 peaked at $8.8 \mathrm{kcal} \mathrm{mol}^{-1}$. Finally, a C-C bondformation step generates the desired product $\mathbf{P}$ through ${ }^{3}$ TS5 with an energy barrier of $35.1 \mathrm{kcal} \mathrm{mol}^{-1}$, which is the ratedetermining step in the reaction. This result is in line with the experimental conditions in which high temperature is required for this reaction. Moreover, the total $\Delta G_{298}$, rxn in 1,4-dioxane of this reaction is $-77.3 \mathrm{kcal} \mathrm{mol}^{-1}$ overall, accounting for a thermodynamically favorable process. The calculation results support that this reaction proceeds involving a biradical reaction mechanism in a triplet. In addition, we calculated another possible triplet biradical mediated reaction mechanism which is also supported by the DFT calculations (Scheme S8 in the ESI $\dagger$ ). In this mechanism, the energy barrier of the rate-determining step is $45.5 \mathrm{kcal} \mathrm{mol}^{-1}$, and the total $\Delta G_{298}$, rxn in 1,4-dioxane of this reaction is $-77.3 \mathrm{kcal} \mathrm{mol}^{-1}$ overall. Through the comparison of these two ionic reactions, we conclude that the mechanism shown in Scheme 3 is more reasonable than the mechanism shown in Scheme S8. $\dagger$

To verify the reaction mechanism, two control experiments were conducted, and the results are shown in Scheme 4. Using butylated hydroxytoluene (BHT) and 2,2,6,6-tetramethylpiperidinooxy (TEMPO) as radical inhibitors, the yields of desired product $2 \mathrm{a}$ obtained were $40 \%$ and $27 \%$, respectively

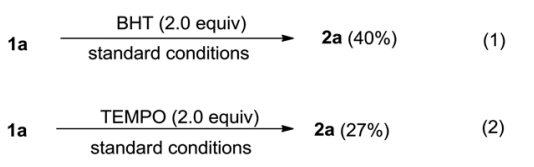

Scheme 4 Control experiments. under the standard conditions. The extent of quenching is not significant. Based on our proposal, the biradical intermediate is generated in an intramolecular manner; thus, it is difficult to quench significantly by TEMPO.

\section{Conclusions}

In conclusion, we have discovered a novel triplet biradical mediated dimerization-cyclization reaction of isocyanoaryltethered alkylidenecyclobutanes, furnishing macrocyclic products containing dihydroquinoline and quinoline units in moderate yields. This new synthetic protocol represents a new entry for the rapid construction of macrocyclic skeletons with simple substrates. Further investigations on expanding the applications of this synthetic method are ongoing in our laboratory.

\section{Conflicts of interest}

There are no conflicts to declare.

\section{Acknowledgements}

We are grateful for the financial support from the Strategic Priority Research Program of the Chinese Academy of Sciences (Grant No. XDB20000000) and the National Natural Science Foundation of China (21372250, 21121062, 21302203, 20732008, 21772037, 21772226, 21861132014 and 91956115). 


\section{References}

1 For selected reviews on isocyanides, see: (a) A. Dömling, Recent Developments in Isocyanide Based Multicomponent Reactions in Applied Chemistry, Chem. Rev., 2006, 106, 1789; (b) A. V. Gulevich, A. G. Zhdanko, R. V. A. Orru and V. G. Nenajdenko, Isocyanoacetate Derivatives: Synthesis, Reactivity, and Application, Chem. Rev., 2010, 110, 52355331; (c) A. V. Lygin and A. de Meijere, Isocyanides in the Synthesis of Nitrogen Heterocycles, Angew. Chem., Int. Ed., 2010, 49, 9094-9124; (d) S. Sadjadi and M. M. Heravi, Recent application of isocyanides in synthesis of heterocycles, Tetrahedron, 2011, 67, 2707-2752; (e) N. Selander and K. J. Szabó, Catalysis by Palladium Pincer Complexes, Chem. Rev., 2011, 111, 2048-2076; $(f)$ T. Vlaar, E. Ruijter, B. U. W. Maes and R. V. A. Orru, Palladium-Catalyzed Migratory Insertion of Isocyanides: An Emerging Platform in Cross-Coupling Chemistry, Angew. Chem., Int. Ed., 2013, 52, 7084-7097; $(g)$ S. Chakrabarty, S. Choudhary, A. Doshi, F.-Q. Liu, R. Mohan, M. P. Ravindra, D. Shah, X. Yang and F. F. Fleming, Catalytic Isonitrile Insertions and Condensations Initiated by RNC-X Complexation, Adv. Synth. Catal., 2014, 356, 2135-2196; (h) V. P. Boyarskiy, N. A. Bokach, K. V. Luzyanin and V. Y. Kukushkin, MetalMediated and Metal-Catalyzed Reactions of Isocyanides, Chem. Rev., 2015, 115, 2698-2779; (i) B. Zhang and A. Studer, Recent advances in the synthesis of nitrogen heterocycles via radical cascade reactions using isonitriles as radical acceptors, Chem. Soc. Rev., 2015, 44, 3505-3521; (j) X. Sun and S. Yu, Visible-Light-Promoted and Photoredox-Catalyzed Radical Addition to Triple Bonds, Synlett, 2016, 2659-2675; (k) B. Song and B. Xu, Metal-catalyzed C-H functionalization involving isocyanides, Chem. Soc. Rev., 2017, 46, 1103-1123; (l) J. W. Collet, T. R. Roose, E. Ruijter, B. U. W. Maes and R. V. A. Orru, Base Metal Catalyzed Isocyanide Insertions, Angew. Chem., Int. Ed., 2020, 59, 540-558.

2 For selected articles on insertion into chemical bonds of isocyanides, see: (a) E. Barnea, T. Andrea, M. Kapon, J.-C. Berthet, M. Ephritikhine and M. S. Eisen, Catalytic Coupling of Terminal Alkynes with Isonitriles Promoted by Organoactinide Complexes, J. Am. Chem. Soc., 2004, 126, 10860-10861; (b) K. Komeyama, D. Sasayama, T. Kawabata, K. Takehira and K. Takaki, Direct mono-insertion of isocyanides into terminal alkynes catalyzed by rare-earth silylamides, Chem. Commun., 2005, 634-636, DOI: 10.1039/ B414302G; (c) K. Komeyama, D. Sasayama, T. Kawabata, K. Takehira and K. Takaki, Rare-Earth Silylamide-Catalyzed Monocoupling Reaction of Isocyanides with Terminal Alkynes, J. Org. Chem., 2005, 70, 10679-10687; (d) W.-X. Zhang, M. Nishiura and Z. Hou, Synthesis of (Z)-1Aza-1,3-enynes by the Cross-Coupling of Terminal Alkynes with Isocyanides Catalyzed by Rare-Earth Metal Complexes, Angew. Chem., Int. Ed., 2008, 47, 9700-9703; (e) T. Nanjo, C. Tsukano and Y. Takemoto, Palladium-Catalyzed Cascade Process Consisting of Isocyanide Insertion and Benzylic
C(sp3)-H Activation: Concise Synthesis of Indole Derivatives, Org. Lett., 2012, 14, 4270-4273; $(f)$ J. Peng, L. Liu, Z. Hu, J. Huang and Q. Zhu, Direct carboxamidation of indoles by palladium-catalyzed $\mathrm{C}-\mathrm{H}$ activation and isocyanide insertion, Chem. Commun., 2012, 48, 3772-3774; (g) G. Qiu, Q. Ding and J. Wu, Recent advances in isocyanide insertion chemistry, Chem. Soc. Rev., 2013, 42, 52575269; (h) X. Huang, S. Xu, Q. Tan, M. Gao, M. Li and B. Xu, A copper-mediated tandem reaction through isocyanide insertion into $\mathrm{N}-\mathrm{H}$ bonds: efficient access to unsymmetrical tetrasubstituted ureas, Chem. Commun., 2014, 50, 14651468; (i) T.-H. Zhu, X.-P. Xu, J.-J. Cao, T.-Q. Wei, S.-Y. Wang and S.-J. Ji, Cobalt(II)-Catalyzed Isocyanide Insertion Reaction with Amines under Ultrasonic Conditions: A Divergent Synthesis of Ureas, Thioureas and Azaheterocycles, Adv. Synth. Catal., 2014, 356, 509-518; (j) T.-H. Zhu, S.-Y. Wang, T.-Q. Wei and S.-J. Ji, CobaltCatalyzed Intermolecular Oxidative Isocyanide Insertion with Two Amines: An Approach to Guanidines, Adv. Synth. Catal., 2015, 357, 823-828; (k) P. Bora and G. Bez, Chemoselective isocyanide insertion into the $\mathrm{N}-\mathrm{H}$ bond using iodine-DMSO: metal-free access to substituted ureas, Chem. Commun., 2018, 54, 8363-8366; (l) W. Hu, M. Li, G. Jiang, W. Wu and H. Jiang, Synthesis of 2,3Difunctionalized Benzofuran Derivatives through Palladium-Catalyzed Double Isocyanide Insertion Reaction, Org. Lett., 2018, 20, 3500-3503; (m) S. Luo, Z. Xiong, Y. Lu and Q. Zhu, Enantioselective Synthesis of Planar Chiral Pyridoferrocenes via Palladium-Catalyzed Imidoylative Cyclization Reactions, Org. Lett., 2018, 20, 1837-1840; (n) L. Zhang, J. Li, Z. Hu, J. Dong, X.-M. Zhang and X. Xu, Silver-Catalyzed Isocyanide Insertion into $\mathrm{N}-\mathrm{H}$ Bond of Ammonia: $[5+1]$ Annulation to Quinazoline Derivatives, Adv. Synth. Catal., 2018, 360, 1938-1942; (o) R. Zhang, Z.-Y. Gu, S.-Y. Wang and S.-J. Ji, Co(II)/Ag(I) Synergistically Catalyzed Monoinsertion Reaction of Isocyanide to Terminal Alkynes with H2O: Synthesis of Alkynamide Derivatives, Org. Lett., 2018, 20, 5510-5514; ( $p$ ) H. Chi, H. Li, B. Liu, R. Ye, H. Wang, Y.-L. Guo, Q. Tan and B. Xu, From Isocyanides to Iminonitriles via Silver-mediated Sequential Insertion of C(sp3)-H Bond, iScience, 2019, 21, 650-663; (q) W. Hu, F. Teng, H. Hu, S. Luo and Q. Zhu, PdCatalyzed C(sp2)-H Imidoylative Annulation: A General Approach To Construct Dibenzoox(di)azepines, J. Org. Chem., 2019, 84, 6524-6535; (r) F. Teng, W. Hu, H. Hu, S. Luo and Q. Zhu, Selective $\mathrm{C}-\mathrm{H}$ or $\mathrm{N}-\mathrm{H}$ Imidoylative Annulation of 2-(2-Isocyanophenyl)-1H-indoles Leading to Diverse Indole-fused Scaffolds, Adv. Synth. Catal., 2019, 361, 1414-1418; (s) L. Zhao, B. Liu, Q. Tan, C.-H. Ding and B. Xu, Silver-Assisted Oxidative Isocyanide Insertion of Ethers: A Direct Approach to $\beta$-Carbonyl $\alpha$-Iminonitriles, Org. Lett., 2019, 21, 9223-9227; ( $t$ ) J. W. Collet, B. Morel, H.-C. Lin, T. R. Roose, P. Mampuys, R. V. A. Orru, E. Ruijter and B. U. W. Maes, Synthesis of Densely Functionalized Pyrimidouracils by Nickel(II)-Catalyzed Isocyanide Insertion, Org. Lett., 2020, 22, 914-919. 
3 For selected articles on radical cyclization of isocyanides, see: (a) M. Tobisu, K. Koh, T. Furukawa and N. Chatani, Modular Synthesis of Phenanthridine Derivatives by Oxidative Cyclization of 2-Isocyanobiphenyls with Organoboron Reagents, Angew. Chem., Int. Ed., 2012, 51, 11363-11366; (b) B. Zhang, C. Mück-Lichtenfeld, C. G. Daniliuc and A. Studer, 6-TrifluoromethylPhenanthridines through Radical Trifluoromethylation of Isonitriles, Angew. Chem., Int. Ed., 2013, 52, 10792-10795; (c) Y. Cheng, X. Yuan, H. Jiang, R. Wang, J. Ma, Y. Zhang and S. Yu, Regiospecific Synthesis of 1-Trifluoromethylisoquinolines Enabled by Photoredox Somophilic Vinyl Isocyanide Insertion, Adv. Synth. Catal., 2014, 356, 2859-2866; (d) J. Liu, C. Fan, H. Yin, C. Qin, G. Zhang, X. Zhang, H. Yi and A. Lei, Synthesis of 6-acyl phenanthridines by oxidative radical decarboxylation-cyclization of $\alpha$-oxocarboxylates and isocyanides, Chem. Commun., 2014, 50, 2145-2147; (e) H. Wang, Y. Yu, X. Hong and B. $\mathrm{Xu}, \mathrm{Mn}(\mathrm{ii}) / \mathrm{O} 2$-promoted oxidative annulation of vinyl isocyanides with boronic acids: synthesis of multisubstituted isoquinolines, Chem. Commun., 2014, 50, 13485-13488; $(f)$ K. Tong, T. Zheng, Y. Zhang and S. Yu, Synthesis of ortho-(Fluoro)alkylated Pyridines via Visible Light-Promoted Radical Isocyanide Insertion, Adv. Synth. Catal., 2015, 357, 3681-3686; (g) H. Mao, M. Gao, B. Liu and B. Xu, Manganese(II)-catalyzed modular synthesis of isoquinolines from vinyl isocyanides and hydrazines, Org. Chem. Front., 2016, 3, 516-521; (h) P. Xiao, J. Rong, C. Ni, J. Guo, X. Li, D. Chen and J. Hu, Radical (Phenylsulfonyl) difluoromethylation of Isocyanides with PhSO2CF2H under Transition-Metal-Free Conditions, Org. Lett., 2016, 18, 5912-5915; (i) Y.-C. Yuan, H.-L. Liu, X.-B. Hu, Y. Wei and M. Shi, Visible-Light-Induced Trifluoromethylation of Isonitrile-Substituted Methylenecyclopropanes: Facile Access to 6-(Trifluoromethyl)-7,8-Dihydrobenzo[k]phenanthridine Derivatives, Chem. - Eur. J., 2016, 22, 1305913063; (j) D. Li, T. Mao, J. Huang and Q. Zhu, Denitrogenative Imidoyl Radical Cyclization: Synthesis of 2-Substituted Benzoimidazoles from 1-Azido-2-isocyanoarenes, Org. Lett., 2017, 19, 3223-3226; (k) X. Liu, Z. Wu, Z. Zhang, P. Liu and P. Sun, Synthesis of trifluoroalkyl or difluoroalkyl phenanthridine derivatives via cascade reaction using an intramolecular cyano group as a radical acceptor under photoredox catalysis, Org. Biomol. Chem., 2018, 16, 414-423; (l) W.-C. Yang, K. Wei, X. Sun, J. Zhu and L. Wu, Cascade C(sp3)-S Bond Cleavage and Imidoyl C-S Formation: Radical Cyclization of 2-Isocyanoaryl Thioethers toward 2-Substituted Benzothiazoles, Org. Lett., 2018, 20, 3144-3147; ( $m$ ) P. Xu, Y.-M. Zhu, F. Wang, S.-Y. Wang and S.-J. Ji, Mn(III)-Mediated Cascade Cyclization of 3-Isocyano-[1,1'-biphenyl]-2-carbonitrile with Arylboronic Acid: Construction of Pyrrolopyridine Derivatives, Org. Lett., 2019, 21, 683-686.

4 For selected articles on functioning as ligands of isocyanides, see: (a) T. Seki, K. Kobayashi, T. Mashimo and H. Ito, A gold isocyanide complex with a pendant carboxy group: orthogonal molecular arrangements and hypsochromically shifted luminescent mechanochromism, Chem. Commun., 2018, 54, 11136-11139; (b) G. Szczepaniak, A. Ruszczyńska, K. Kosiński, E. Bulska and K. Grela, Highly efficient and time economical purification of olefin metathesis products from metal residues using an isocyanide scavenger, Green Chem., 2018, 20, 1280-1289; (c) T. Tominaga and T. Mochida, Multifunctional Ionic Liquids from Rhodium(I) Isocyanide Complexes: Thermochromic, Fluorescence, and Chemochromic Properties Based on Rh-Rh Interaction and Oxidative Addition, Chem. - Eur. J., 2018, 24, 6239-6247; (d) Q. Wan, W.-P. To, C. Yang and C.-M. Che, The Metal-Metal-toLigand Charge Transfer Excited State and Supramolecular Polymerization of Luminescent Pincer PdII-Isocyanide Complexes, Angew. Chem., Int. Ed., 2018, 57, 3089-3093; (e) K. T. Mahmudov, V. Y. Kukushkin, A. V. Gurbanov, M. A. Kinzhalov, V. P. Boyarskiy, M. F. C. G. da Silva and A. J. L. Pombeiro, Isocyanide metal complexes in catalysis, Coord. Chem. Rev., 2019, 384, 65-89; (f) A. Sanagawa and H. Nagashima, Hydrosilane Reduction of Nitriles to Primary Amines by Cobalt-Isocyanide Catalysts, Org. Lett., 2019, 21, 287-291.

5 For selected articles on acting as zwitterion intermediate of isocyanides, see: (a) S. Kamijo, T. Jin and Y. Yamamoto, Novel Synthetic Route to Allyl Cyanamides: PalladiumCatalyzed Coupling of Isocyanides, Allyl Carbonate, and Trimethylsilyl Azide, J. Am. Chem. Soc., 2001, 123, 94539454; (b) M. Tobisu, S. Imoto, S. Ito and N. Chatani, Palladium-Catalyzed Cyclocoupling of 2-Halobiaryls with Isocyanides via the Cleavage of Carbon-Hydrogen Bonds, J. Org. Chem., 2010, 75, 4835-4840; (c) Y. Fukumoto, M. Hagihara, F. Kinashi and N. Chatani, Switch in Stereoselectivity Caused by the Isocyanide Structure in the Rhodium-Catalyzed Silylimination of Alkynes, J. Am. Chem. Soc., 2011, 133, 10014-10017; (d) S. Lang, Unravelling the labyrinth of palladium-catalysed reactions involving isocyanides, Chem. Soc. Rev., 2013, 42, 4867-4880; (e) Y. Odabachian, S. Tong, Q. Wang, M.-X. Wang and J. Zhu, Zinc Bromide Promoted Coupling of Isonitriles with Carboxylic Acids To Form 2,4,5-Trisubstituted Oxazoles, Angew. Chem., Int. Ed., 2013, 52, 10878-10882; (f) Y.-J. Liu, H. Xu, W.-J. Kong, M. Shang, H.-X. Dai and J.-Q. Yu, Overcoming the limitations of directed $\mathrm{C}-\mathrm{H}$ functionalizations of heterocycles, Nature, 2014, 515, 389-393; ( $g$ ) J. Kim and S. H. Hong, Organocatalytic activation of isocyanides: N-heterocyclic carbene-catalyzed enaminone synthesis from ketones, Chem. Sci., 2017, 8, 2401-2406; (h) Q. Xiong, S. Dong, Y. Chen, X. Liu and X. Feng, Asymmetric synthesis of tetrazole and dihydroisoquinoline derivatives by isocyanide-based multicomponent reactions, Nat. Commun., 2019, 10, 2116; (i) Q. Xiong, G. Li, S. Dong, X. Liu and X. Feng, Enantioselective Synthesis of Hydrothiazole Derivatives via an IsocyanideBased Multicomponent Reaction, Org. Lett., 2019, 21, 87718775. 
6 For selected articles on multi-component reactions of isocyanides, see: (a) G. Qiu, Y. He and J. Wu, Preparation of quinazolino[3,2-a]quinazolines via a palladium-catalyzed three-component reaction of carbodiimide, isocyanide, and amine, Chem. Commun., 2012, 48, 3836-3838; (b) P. Dang, W. Zeng and Y. Liang, Copper-Catalyzed Three-Component Synthesis of Benzothiazolethiones from o-Iodoanilines, Isocyanide, and Potassium Sulfide, Org. Lett., 2015, 17, 3437; (c) A. L. Chandgude and A. Dömling, Unconventional Passerini Reaction toward $\alpha$-Aminoxy-amides, Org. Lett., 2016, 18, 6396-6399; (d) Q. Gao, W.-J. Hao, F. Liu, S.-J. Tu, S.-L. Wang, G. Li and B. Jiang, Unexpected isocyanidebased three-component bicyclization for the stereoselective synthesis of densely functionalized pyrano[3,4-c]pyrroles, Chem. Commun., 2016, 52, 900-903; (e) T. Kaur, P. Wadhwa, S. Bagchi and A. Sharma, Isocyanide based $[4+1]$ cycloaddition reactions: an indispensable tool in multi-component reactions (MCRs), Chem. Commun., 2016, 52, 69586976; $(f)$ H. R. Safaei and F. Dehbozorgi, Isocyanide-based three component reaction for synthesis of highly cyano substituted furan derivatives, $R S C A d v ., 2016,6$, 2678326790; $(g)$ H.-Y. Wang, M. Bao, B. Jiang and L. Li, Basemediated isocyanide-based three-component reactions: divergent synthesis of spiro-substituted furans and pyrroles, $R S C A d v$., 2016, 6, 6459-6466; (h) A. L. Chandgude and A. Dömling, N-Hydroxyimide Ugi Reaction toward $\alpha$-Hydrazino Amides, Org. Lett., 2017, 19, 1228-1231; (i) T. A. Nizami and R. Hua, Synthesis of 3H-naphtho[2.1-b] pyran-2-carboxamides from cyclocoupling of $\beta$-naphthol, propargyl alcohols and isocyanide in the presence of Lewis acids, Tetrahedron, 2018, 74, 3776-3780; (j) Z.-L. Ren, P. He, W.-T. Lu, M. Sun and M.-W. Ding, Synthesis of iminoisoindolinones via a cascade of the three-component Ugi reaction, palladium catalyzed isocyanide insertion, hydroxylation and an unexpected rearrangement reaction, Org. Biomol. Chem., 2018, 16, 6322-6331; (k) D. M. Sawant, S. Sharma, R. S. Pathare, G. Joshi, S. Kalra, S. Sukanya, A. K. Maurya, R. K. Metre, V. K. Agnihotri, S. Khan, R. Kumar and R. T. Pardasani, Relay tricyclic Pd(ii)/Ag(i) catalysis: design of a four-component reaction driven by nitrene-transfer on isocyanide yields inhibitors of EGFR, Chem. Commun., 2018, 54, 11530-11533; (l) V. B. K. Kunig, C. Ehrt, A. Dömling and A. Brunschweiger, Isocyanide Multicomponent Reactions on Solid-Phase-Coupled DNA Oligonucleotides for Encoded Library Synthesis, Org. Lett., 2019, 21, 7238-7243; ( $m$ ) Y. Wang, P. Patil, K. Kurpiewska, J. Kalinowska-Tluscik and A. Dömling, Diverse Isoquinoline Scaffolds by Ugi/Pomeranz-Fritsch and Ugi/ Schlittler-Müller Reactions, Org. Lett., 2019, 21, 3533-3537.

7 For selected articles on dimerization reaction of isocyanides, see: (a) G. Höfle and B. Lange, N-Imidoyl Isocyanides, Angew. Chem., Int. Ed. Engl., 1977, 16, 727-728; (b) C. Kanazawa, S. Kamijo and Y. Yamamoto, Synthesis of Imidazoles through the Copper-Catalyzed CrossCycloaddition between Two Different Isocyanides, J. Am. Chem. Soc., 2006, 128, 10662-10663; (c) N. Shao,
G.-X. Pang, X.-R. Wang, R.-J. Wu and Y. Cheng, Dimerization of 2-pyridylisonitriles produces $\pi$-extended fused heteroarenes useful as highly selective colorimetric and optical probes for copper ion, Tetrahedron, 2010, 66, 7302-7308; (d) B. Pooi, J. Lee, K. Choi, H. Hirao and S. H. Hong, Tandem Insertion-Cyclization Reaction of Isocyanides in the Synthesis of 1,4-Diaryl-1H-imidazoles: Presence of N-Arylformimidate Intermediate, J. Org. Chem., 2014, 79, 9231-9245; (e) Z. Hu, H. Yuan, Y. Men, Q. Liu, J. Zhang and X. Xu, Cross-Cycloaddition of Two Different Isocyanides: Chemoselective Heterodimerization and $[3+$ 2]-Cyclization of 1,4-Diazabutatriene, Angew. Chem., Int. Ed., 2016, 55, 7077-7080; (f) Y. Gao, Z. Hu, J. Dong, J. Liu and $\mathrm{X}$. $\mathrm{Xu}$, Chemoselective Double Annulation of Two Different Isocyanides: Rapid Access to Trifluoromethylated Indole-Fused Heterocycles, Org. Lett., 2017, 19, 5292-5295; (g) Z. Hu, J. Dong, Y. Men, Z. Lin, J. Cai and X. Xu, SilverCatalyzed Chemoselective $[4+2]$ Annulation of Two Isocyanides: A General Route to Pyridone-Fused Carbo- and Heterocycles, Angew. Chem., Int. Ed., 2017, 56, 1805-1809; (h) S. Su, J. Hu, Y. Cui, C. Tang, Y. Chen and J. Li, A formal $(5+1)$ annulation reaction from heterodimerization of two different isocyanides: stereoselective synthesis of $2 \mathrm{H}$-benzo [b][1,4] oxazin-2-one, Chem. Commun., 2019, 55, 1224312246; (i) Z. Wang, X.-H. Meng, P. Liu, W.-Y. Hu and Y.-L. Zhao, Rhodium-catalyzed homodimerization-cyclization reaction of two vinyl isocyanides: a general route to 2(isoquinolin-1-yl)oxazoles, Org. Chem. Front., 2020, 7, 126130.

8 H.-L. Liu, Y.-C. Yuan, Y. Wei and M. Shi, Synthesis of 1,2Dihydrocyclobuta[b]quinoline Derivatives from Isocyanophenyl-Substituted Methylenecyclopropanes, Adv. Synth. Catal., 2017, 359, 3437-3443.

9 (a) S. Eswaran, A. V. Adhikari, I. H. Chowdhury, N. K. Pal and K. D. Thomas, New quinoline derivatives: Synthesis and investigation of antibacterial and antituberculosis properties, Eur. J. Med. Chem., 2010, 45, 3374-3383; (b) Y.-Q. Hu, S. Zhang, Z. Xu, Z.-S. Lv, M.-L. Liu and L.-S. Feng, 4-Quinolone hybrids and their antibacterial activities, Eur. J. Med. Chem., 2017, 141, 335-345; (c) G.-F. Zhang, X. Liu, S. Zhang, B. Pan and M.-L. Liu, Ciprofloxacin derivatives and their antibacterial activities, Eur. J. Med. Chem., 2018, 146, 599-612; (d) G.-F. Zhang, S. Zhang, B. Pan, X. Liu and L.-S. Feng, 4-Quinolone derivatives and their activities against Gram positive pathogens, Eur. J. Med. Chem., 2018, 143, 710-723.

10 (a) C. S. Prabodh, C. Monika, S. Archana, P. Mona, R. Harish and P. Om, Insight View on Possible Role of Fluoroquinolones in Cancer Therapy, Curr. Top. Med. Chem., 2013, 13, 2076-2096; (b) O. Afzal, S. Kumar, M. R. Haider, M. R. Ali, R. Kumar, M. Jaggi and S. Bawa, A review on anticancer potential of bioactive heterocycle quinoline, Eur. J. Med. Chem., 2015, 97, 871-910; (c) Z. Zhang, X. Xiao, T. Su, J. Wu, J. Ren, J. Zhu, X. Zhang, R. Cao and R. Du, Synthesis, structure-activity relationships and preliminary mechanism of action of novel water-soluble 4-qui- 
nolone-3-carboxamides as antiproliferative agents, Eur. J. Med. Chem., 2017, 140, 239-251.

11 (a) Z. G. Luo, J. J. Tan, Y. Zeng, C. X. Wang and L. M. Hu, Development of Integrase Inhibitors of Quinolone Acid Derivatives for Treatment of AIDS: An Overview, Mini-Rev. Med. Chem., 2010, 10, 1046-1057; (b) K. C. Sekgota, S. Majumder, M. Isaacs, D. Mnkandhla, H. C. Hoppe, S. D. Khanye, F. H. Kriel, J. Coates and P. T. Kaye, Application of the Morita-Baylis-Hillman reaction in the synthesis of 3 -[(N-cycloalkylbenzamido)methyl]-2-quinolones as potential HIV-1 integrase inhibitors, Bioorg. Chem., 2017, 75, 310-316.

12 (a) K. Kaur, M. Jain, R. P. Reddy and R. Jain, Quinolines and structurally related heterocycles as antimalarials, Eur. J. Med. Chem., 2010, 45, 3245-3264; (b) S. Mukherjee and M. Pal, Quinolines: a new hope against inflammation, Drug Discovery Today, 2013, 18, 389-398; (c) R. Cannalire, M. L. Barreca, G. Manfroni and V. Cecchetti, A Journey around the Medicinal Chemistry of Hepatitis C Virus Inhibitors Targeting NS4B: From Target to Preclinical Drug Candidates, J. Med. Chem., 2016, 59, 16-41; (d) Y.-Q. Hu, C. Gao, S. Zhang, L. Xu, Z. Xu, L.-S. Feng, X. Wu and F. Zhao, Quinoline hybrids and their antiplasmodial and antimalarial activities, Eur. J. Med. Chem., 2017, 139, 22-47; (e) Z. Xu, S. Zhang, C. Gao, J. Fan, F. Zhao, Z.-S. Lv and L.-S. Feng, Isatin hybrids and their anti-tuberculosis activity, Chin. Chem. Lett., 2017, 28, 159-167; (f) S. Zhang, Z. Xu, C. Gao, Q.-C. Ren, L. Chang, Z.-S. Lv and L.-S. Feng, Triazole derivatives and their anti-tubercular activity, Eur. J. Med. Chem., 2017, 138, 501-513; (g) Y.-L. Fan, X.-W. Cheng, J.-B. Wu, M. Liu, F.-Z. Zhang, Z. Xu and L.-S. Feng, Antiplasmodial and antimalarial activities of quinolone derivatives: An overview, Eur. J. Med. Chem., 2018, 146, 1-14; (h) Y.-L. Fan, J.-B. Wu, X.-W. Cheng, F.-Z. Zhang and L.-S. Feng, Fluoroquinolone derivatives and their anti-tubercular activities, Eur. J. Med. Chem., 2018, 146, 554-563; (i) K. D. Upadhyay, N. M. Dodia, R. C. Khunt, R. S. Chaniara and A. K. Shah, Synthesis and Biological Screening of Pyrano[3,2-c]quinoline Analogues as Anti-inflammatory and Anticancer Agents, ACS Med. Chem. Lett., 2018, 9, 283-288; (j) Z. Wang, J. Hu, X. Yang, X. Feng, X. Li, L. Huang and A. S. C. Chan, Design, Synthesis, and Evaluation of Orally Bioavailable QuinolineIndole Derivatives as Innovative Multitarget-Directed Ligands: Promotion of Cell Proliferation in the Adult Murine Hippocampus for the Treatment of Alzheimer's Disease, J. Med. Chem., 2018, 61, 1871-1894.

13 K. S. S. Praveena, E. V. V. Shivaji Ramarao, N. Y. S. Murthy, S. Akkenapally, C. Ganesh Kumar, R. Kapavarapu and S. Pal, Design of new hybrid template by linking quinoline, triazole and dihydroquinoline pharmacophoric groups: A greener approach to novel polyazaheterocycles as cytotoxic agents, Bioorg. Med. Chem. Lett., 2015, 25, 1057-1063.

14 For selected articles on synthesis of quinoline, see: (a) X.-D. An and S. Yu, Visible-Light-Promoted and One-Pot Synthesis of Phenanthridines and Quinolines from
Aldehydes and O-Acyl Hydroxylamine, Org. Lett., 2015, 17, 2692-2695; (b) Y. Chi, H. Yan, W.-X. Zhang and Z. Xi, Synthesis of Quinoline Derivatives via Cu-Catalyzed Cascade Annulation of Heterocumulenes, Alkynes, and Diaryliodonium Salts, Org. Lett., 2017, 19, 2694-2697; (c) J. Jin, S. Guidi, Z. Abada, Z. Amara, M. Selva, M. W. George and M. Poliakoff, Continuous niobium phosphate catalysed Skraup reaction for quinoline synthesis from solketal, Green Chem., 2017, 19, 2439-2447; (d) J. V. Jun, E. J. Petersson and D. M. Chenoweth, Rational Design and Facile Synthesis of a Highly Tunable QuinolineBased Fluorescent Small-Molecule Scaffold for Live Cell Imaging, J. Am. Chem. Soc., 2018, 140, 9486-9493; (e) L. Zheng, Z. Zeng, Q. Yan, F. Jia, L. Jia and Y. Chen, Copper-Catalyzed Synthesis of 3-NO2 Quinolines from o-Azidobenzaldehyde and Nitro-olefins and its Application in the Concise Synthesis of Quindolines, Adv. Synth. Catal., 2018, 360, 4037-4042; (f) B. Bieszczad, L. A. Perego and P. Melchiorre, Photochemical C-H Hydroxyalkylation of Quinolines and Isoquinolines, Angew. Chem., Int. Ed., 2019, 58, 16878-16883; (g) Z. Ma, T. Song, Y. Yuan and Y. Yang, Correction: Synergistic catalysis on $\mathrm{Fe}-\mathrm{Nx}$ sites and $\mathrm{Fe}$ nanoparticles for efficient synthesis of quinolines and quinazolinones via oxidative coupling of amines and aldehydes, Chem. Sci., 2019, 10, 10653-10653; (h) J. Wan, H. Liu, Y. Lan, X. Li, X. Hu, J. Li, H.-P. Xiao and J. Jiang, Catalytic Asymmetric Synthesis of Atropisomeric Quinolines through the Friedländer Reaction, Synlett, 2019, 2198-2202; (i) Y. Wu, X. Lu, H. Wang, E. Liang, Y. Yuan, Q. Zhao, Z. Zhu, J. Huang and X. Tang, Acid-Catalyzed Synthesis of Quinoline Derivatives from 2-Methylquinolines and 2-Aryloxy/Alkoxybenzaldehyde in Aqueous Medium, Eur. J. Org. Chem., 2019, 7452-7462; (j) S. Guo, L. Sun, X. Li, X. Zhang and X. Fan, Selective Synthesis of Indazolo[2,3-a]quinolines via $\mathrm{Rh}(\mathrm{III})$-Catalyzed Oxidant-Free $[4+2]$ or $[5+1]$ Annulation of 2-Aryl-2H-indazoles with $\alpha$-Diazo Carbonyl Compounds, Adv. Synth. Catal., 2020, 362, 913-926; (k) X. Tian, L. Song, K. Farshadfar, M. Rudolph, F. Rominger, T. Oeser, A. Ariafard and A. S. K. Hashmi, Acyl Migration versus Epoxidation in Gold Catalysis: Facile, Switchable, and Atom-Economic Synthesis of Acylindoles and Quinoline Derivatives, Angew. Chem., Int. Ed., 2020, 59, 471-478.

15 For selected articles on synthesis of dihydroquinoline, see: (a) N. Purkait and S. Blechert, Synthesis of Bi- and Tricyclic 1,2-Dihydroquinoline Derivatives from Arylamines and Alkynes by a Consecutive Zinc-Ammonium Salt Catalysis, Adv. Synth. Catal., 2012, 354, 2079-2083; (b) X.-Q. Chu, Y. Zi, H. Meng, X.-P. Xu and S.-J. Ji, Synthesis of 1,4-dihydroquinoline derivatives under transition-metal-free conditions and their diverse applications, Org. Biomol. Chem., 2014, 12, 4243-4251; (c) S. J. Gharpure, V. Prasath and V. Kumar, Stereoselective synthesis of 2,3-disubstituted indoline, pyrrolidine and cyclic ether-fused 1,2-dihydroquinoline derivatives using alkyne iminium ion cyclization of vinylogous carbamates: switch of regioselectivity using an internal hydroxy group as a nucleophile, Chem. Commun., 
2015，51，13623-13626; (d) Y.-F. Qiu, X.-R. Song, M. Li, X.-Y. Zhu, A.-Q. Wang, F. Yang, Y.-P. Han, H.-R. Zhang, D.-P. Jin, Y.-X. Li and Y.-M. Liang, BF BF $_{3} \mathrm{OEt}_{2}-\mathrm{AgSCF}_{3}$ Mediated Trifluoromethylthiolation/Cascade Cyclization of Propynols: Synthesis of 4-((Trifluoromethyl)thio)-2H-chromene and 4-((Trifluoromethyl)thio)-1,2-dihydroquinoline Derivatives, Org. Lett., 2016, 18, 1514-1517; (e) M. V. Reddy, N. T. K. Lien, G. C. S. Reddy, K. T. Lim and Y. T. Jeong, Polymer grafted layered double hydroxides (LDHs-gPOEGMA): a highly efficient reusable solid catalyst for the synthesis of chromene incorporated dihydroquinoline derivatives under solvent-free conditions, Green Chem., 2016, 18, 4228-4239; $(f)$ K. Vijay, C. Nandi and S. D. Samant, Synthesis of a dihydroquinoline based fluorescent cyanine for selective, naked eye, and turn off detection of $\mathrm{Fe}^{3+}$ ions, RSC Adv., 2016, 6, 49724-49729; (g) T. Hodík and C. Schneider, Brønsted acid-catalyzed, enantioselective synthesis of 1,4-dihydroquinoline-3-carboxylates via in situ generated ortho-quinone methide imines, Org. Biomol. Chem., 2017, 15, 3706-3716; (h) Z. Kang, D. Zhang and W. Hu, Regio- and Diastereoselective Three-Component Reactions via
Trapping of Ammonium Ylides with N-Alkylquinolinium Salts: Synthesis of Multisubstituted Tetra- and Dihydroquinoline Derivatives, Org. Lett., 2017, 19, 37833786; (i) Z.-L. Zang, S. Karnakanti, S. Zhao, P. Hu, Z. Wang, P.-L. Shao and Y. He, Synthesis of Spiro-dihydroquinoline and Octahydrophenanthrene Derivatives via PalladiumCatalyzed Intramolecular Oxidative Arylation, Org. Lett., 2017, 19, 1354-1357; (j) M. Chen, Y. Wei and M. Shi, A facile method for the synthesis of dihydroquinoline-azide from the Lewis acid-catalyzed reaction of alkylidenecyclopropanes with TMSN3, Org. Biomol. Chem., 2019, 17, 99909993.

16 (a) W. L. Jorgensen and L. Salem, The Organic Chemist's Book of Orbital, Academic Press, New York, 1973; (b) C. W. Haigh and R. B. Mallion, Ring current theories in nuclear magnetic resonance, Prog. Nucl. Magn. Reson. Spectrosc., 1979, 13, 303-344; (c) H. N. C. Wong, M. Y. Hon, C. W. Tse, Y. C. Yip, J. Tanko and T. Hudlicky, Use of cyclopropanes and their derivatives in organic synthesis, Chem. Rev., 1989, 89, 165-198.

17 M. J. S. Dewar, Chemical implications of $\sigma$ conjugation, J. Am. Chem. Soc., 1984, 106, 669-682. 